\title{
Prevalence and Contributing Factors of Meconium Stained Amniotic Fluid Among Women Delivered at St Paul's Hospital Millennium Medical College, Addis Ababa, Ethiopia
}

\author{
Hana Abera Hailemariam*1 $\quad$ Frehiwot Nigusse $^{2} \quad$ Ersite Nigussa Gamshe ${ }^{2}$ \\ Boni Assfaw kumsa ${ }^{2} \quad$ Mekdes Hailegebreal Habte ${ }^{3} \quad$ Rahel Nega Kassa ${ }^{4} \quad$ Rediet Workneh ${ }^{5}$ \\ 1.Department of Maternal and Child Health Nursing, Paul's Hospital Millennium Medical Collage, Addis \\ Ababa, Ethiopia \\ 2.Department of Neonatal Nursing,St. Paul's Hospital Millennium Medical Collage, Addis Ababa, Ethiopia \\ 3.Department of Pediatric Nursing, Paul's Hospital Millennium Medical Collage, Addis Ababa, Ethiopia \\ 4.Department of Surgical Nursing, St. Paul's Hospital Millennium Medical Collage, Addis Ababa,Ethiopia \\ 5.Department of Pediatric Paul's Hospital Millennium Medical Collage, Addis Ababa, Ethiopia \\ * Corresponding author \\ Hana Abera Hailemariam, Saint Paul's Hospital Millennium Medical Collage, Addis Ababa, Ethiopia
}

\begin{abstract}
Background: The incidence of meconium-stained amniotic fluid during labor were considered as an indicator of unpleasant condition for the delivery outcomes which leads to mild to severe respiratory problem, which contributed to perinatal and neonatal morbidity and mortality.

Objective: To assess the prevalence of meconium stained amniotic fluid and its contributing factors among mothers who delivered at. St. Paul's Hospital Millennium Medical College.

Methods: Hospital based cross-sectional study design was implemented at St. Paul's Hospital Millennium Medical College from June 26 - July 24,2019. The study respondents were chosen by using systematic random sampling methods. Chart review together with structured interview was implemented to gather the data. Data was entered and analyzed by SPSS versions 20 . Both descriptive \& analytical statistics were calculated. Statistical significance was measured at $\mathrm{P}<0.05$ and the degree of association were assessed by using adjusted odds ratio.

Result: A total of 248 mothers were enrolled in the study with a response rate of $100 \%$. The prevalence of meconium stained amniotic fluid was found $30(12.1 \%)$ with $[95 \% \mathrm{CI}=8.1-16.5$. Women whose premature rapture of membrane $[\mathrm{AOR}=7.6,95 \% \mathrm{Cl}=2.525-23.00]$, preeclampsia $[\mathrm{AOR}=5.4,95 \% \mathrm{Cl}=1.579-19.145$, prolonged premature rapture of membrane $[\mathrm{AOR}=5.1,95 \% \mathrm{Cl}=1.221-22.122]$, duration of labor $>12 \mathrm{hrs}$ $[\mathrm{AOR}=5.1,95 \% \mathrm{C} 1=1.221-22.122]$, prolonged labor $[\mathrm{AOR}=3.0,95 \% \mathrm{CI}=1.075-8.857]$ were associated with meconium stained amniotic fluid in this study.

Conclusion: The finding concludes that meconium stained amniotic fluid was common problem which impose adverse condition to the fetus and newborn. And it is related to maternal factors such as preeclampsia, length of labor, Prolonged Premature Rupture Of Membrane (PPROM), Premature Rupture Of Membrane (PROM) and prolonged labour which increase the incidence of meconium stained amniotic syndrome.
\end{abstract}

Keywords:Meconium, Meconium stained amniotic fluid, St Paul Hospital Millunium Medical College.

DOI: $10.7176 / \mathrm{JHMN} / 87-03$

Publication date:March $31^{\text {st }} 2021$

\section{INTRODUCTION}

\section{Back ground}

Meconium stained liquor (MSL) is the presence of meconium in the uterus during intranatal period. ${ }^{1}$ Conditions such as chronic hypoxia, respiratory acidosis and infection are contributors that result stress the fetus which induce the passage of meconium. ${ }^{2}$

Major Maternal and fetal factors which leads to Meconium stained amniotic fluid (MSAF) include hypertension, gestational diabetes mellitus, maternal chronic respiratory or cardiovascular diseases, post term pregnancy, preeclampsia, eclampsia, oligohydramnios, Intra uterine growth retardation and poor bio physical profile. $^{3}$

MSAF results long and short-term delivery outcomes, which increased the need of neonatal assistance, due to the adverse outcome such as respiratory distress, lower Apgar score, meconium aspiration syndrome, neonatal sepsis and lung disease. ${ }^{2,}{ }^{4}$ The effects of MSAF is not only posing a threat to the fetus or the neonate, but also lead to serious maternal complications include amniotic fluid embolism and puerperal endometritis. ${ }^{5,6}$

Globally the occurrence of meconium stained liquor is increase as the fetal age gets advanced and about 7 to $22 \%$ of full term pregnancy were develop this adverse condition. ${ }^{7}$

Neonate born through MSAF has 100 times more prone to have respiratory problem than those who have 
been born with low risk of obstetric complications and clear fluid. ${ }^{6}$ About 5 million neonatal deaths occur globally per year. Out of these, $90 \%$ of death results from birth asphyxia and other difficulties associated with breathing. Meconium-stained liquor during labor affects $5 \%-25 \%$ of all deliveries. ${ }^{8}$ Which subsequently leads to meconium aspiration syndrome (MAS) in about $5-12 \%$ infants which holds about $12 \%$ of neonatal mortality.

Whenever risk factors are detected timely, labor monitored strictly and prompt decisions are made regarding the timing and way of delivery, in order to reduce morbidity and mortality of neonate due to adverse outcome of MSAF. ${ }^{10,11}$ In order of this it would help stakeholders as an input to design appropriate preventive measures, for further study and may also help policy makers to give emphasis.

Despite the magnitude and associated factors of MSAF were soundly addressed by studies in the industrial countries, at hand small findings shown on the prevalence and contributing factors of MSAF in the developing countries including Ethiopia.

Hence, the purpose of this study was to found out magnitude, contributing factors of meconium stained amniotic fluid and fetal outcome among mothers who delivered at St. Paul's Hospital Millennium Medical College (SPHMMC), Addis Ababa, Ethiopia.

\section{METHODS AND MATERIALS}

\subsection{Study setting and design}

Hospital based cross-sectional study design was conducted among mothers delivered, at SPHMMC AA(Addis Ababa), Ethiopia from Jun 26 to July 24/2019G.C. AA is the capital city of Ethiopia which has 10 sub cities lies on 540 square kilometer surface area and at altitude ranging from 2,100 meter in the southern (Akaki sub city) to 3,000 meter in northern (Entoto) above sea level. Among those sub cities the northern part of the capital city is Gullele sub city in this sub city St .Paul's hospital millennium medical college were found which is the second largest national public general specialized referral hospital located on the way of Piassa to Medhanialem secondary high school straight road way at right side beside to the Ethiopian public health institute.

The hospital was founded in 1961 E.C. by Emperor Hailesilassie with the help of the German Evangelical church by aiming mainly to serve payment free those economically under privileged population. Since 2007 the institution has been starting to train medical, nursing and public health students and named with SPHMMC. Recently it has 350 beds where an average of 300,000 patients per year admitted and treated in its various departments like medical, surgical, emergency, pediatrics, gynecology, obstetrics, NICU (Neonatal Intensive Care Unit). In terms of obstetric care 10,800labor conducted per year. In the NICU there are around 20 beds where preterm, sick baby and KMC care were delivered. The institution has a more than 5 million catchment population and it is under the supervision of Federal Ministry of Health which holds 1200 clinical and nonclinical staff.

\subsection{Sample Size Determination}

Sample size was estimated by single population proportion formula. $\mathrm{P}$ value by considering previous study on prevalence of MSAF at Felegehiwet hospitals the finding was $17.8 \%$ with confidence interval of $95 \%$ CI.Z= 1.96 , and marginal error $=5 \%$ and calculated as below: ${ }^{11}$

$\mathrm{n}=\mathrm{Z}^{2 * \mathrm{P}}(1-\mathrm{p}) / \mathrm{d}^{2}=$

$=(1.96 * 1.96)(0.178)(1-0.178) / 0.05 * 0.05$

$=224.8$

$=225$ and add non respondent rate $10 \%$

$=248$ were included in the study.

Where

$\mathrm{n}=$ is desired sample $=248$

$\mathrm{z}=$ level of significance at $95 \%$ confidence interval $=1.96$

$\mathrm{p}=$ an estimate of the proportion of MSAF delivery $=17.8 \%$

$\mathrm{d}=$ marginal error $=5 \%$

\subsection{Sampling Procedure}

Addis Ababa is a capital city of Ethiopia with greater than 3 million total population. It has 10 sub cities. The health coverage of AA is around $71 \%$ and has 11 federal and regional hospitals. From the 11 hospitals, SPHMMC were randomly selected for the study area. Systematic random sampling was implemented to get respondents from obstetric unit thus the average numbers of mother who gave birth during the data gathering time were 900 and projected based on the previous month HMIS registration book. Then sampling frame was prepared for the maternal record card by ascending order of the numbers. The total number of mothers who gave birth in a month were 900, distributed to the total number of sample size 248 and it nearly 4 . The first woman was selected by lottery method then every $4^{\text {th }}$ woman who gave birth was selected for the stu56696dy. 


\subsection{Data Collection tools and procedures}

Data was collected by questioners developed by reviewing different literatures relevant to the study objective. The questionnaire was arranged in such a way it could addressed independent variables (Socio-demographic characteristics, maternal associated characteristics and fetal related factors) as well as the dependent variable (MSAF). In addition to this check list was developed to guide chart review.

Data was collected by combining structured interview and card review by three BSC nurse and midwives professionals who were trained for purpose of data collection. The data collected from the respondents was on the basis of inclusion criteria in which mothers that had term and cephalic presentation delivery SPHMMC during the data collection period and had medical record with complete information. On the other hand there were excluded mothers who had preterm delivery, breach presentation, in critical condition and not willing to participate in the study.

\subsection{Operational Definition}

Meconium stained amniotic fluid: - according to this study the term MSAF was taken as one of those reported as having MSAF or ticked by yes and zero of those reported not having MSAF or ticked as no. Additionally the grade was taken as it was defined and record to the mother's card by the obstetricians who conducted the deliveries and graded 1, 2 and 3.

\subsection{Data quality management and analysis}

For the validation of the tool pretest were conducted in 12 mothers $(5 \%$ of the sample who delivered at Black lion Hospital). In addition to this the data quality was maintained by data collectors through careful adherence with data collection procedures and daily check up by supervisors for completeness.

The data were checked for its comprehensiveness, reliability and accuracy then entered and analyzed by using SPSS (Statically Package for Social Science) version 20software, for which descriptive statics was summarized by using percentage, ratio, mean, media and frequency. Bivariate analysis was used to check the association between dependent variable (Meconium stained amniotic fluid) with independent variables. Variables which had association with dependent variable at p-value less than 0.2 were entered to multiple logistic regression then significantly associated variables were identified based on p- value less than 0.05 and discussed accordingly.

\section{RESULT}

\subsection{Socio-demographic characteristics}

A total of 248 respondents were enrolled in the study with $100 \%$ response rate. Most of those mothers $(84.3 \%)$ were in the age range of 18-35 yrs. Regarding ethnicity (37.1\%) of women's were Oromo followed by Amhara (33\%). Majority (34.7\%) of the respondents were Orthodox Christian followers in Religion. From those respondents, $(99.2 \%)$ of the laboring mothers were married and $68.5 \%$ house wife (Table 1$)$. 
Table 1: Socio-demograp9iihic characteristics of mothers who delivered at study area during the study period.

\begin{tabular}{|c|c|c|c|}
\hline \multicolumn{2}{|c|}{$\begin{array}{l}\text { Socio-demographic characteristics of the respondents } \\
\qquad(\mathrm{N}=\mathbf{2 4 8})\end{array}$} & \multirow{2}{*}{$\begin{array}{c}\text { Frequency } \\
17\end{array}$} & \multirow{2}{*}{$\begin{array}{r}\text { Percent } \\
6.9\end{array}$} \\
\hline \multirow{3}{*}{ Age } & $<18$ & & \\
\hline & $18-35$ & 209 & 84.3 \\
\hline & $>35$ & 22 & 8.9 \\
\hline \multirow[t]{4}{*}{ Ethnicity of respondents } & Amhara & 83 & 33.5 \\
\hline & Oromo & 92 & 37.1 \\
\hline & Gurage & 56 & 22.6 \\
\hline & Tigray & 17 & 6.9 \\
\hline \multirow[t]{2}{*}{ Residence of respondent } & Urban & 203 & 81.9 \\
\hline & Rural & 45 & 18.1 \\
\hline \multirow[b]{5}{*}{ Religion of respondent } & Orthodox & 86 & 34.7 \\
\hline & Protestant & 82 & 33.1 \\
\hline & Muslim & 47 & 19.0 \\
\hline & Catholic & 31 & 12.5 \\
\hline & Other & 2 & .8 \\
\hline \multirow[t]{2}{*}{ Marital status } & Married & 246 & 99.2 \\
\hline & Separated & 2 & .8 \\
\hline \multirow[t]{6}{*}{ Occupation } & House wife & 170 & 68.5 \\
\hline & Government employee & 28 & 11.3 \\
\hline & NGO employee & 16 & 6.5 \\
\hline & Merchant & 24 & 9.7 \\
\hline & Student & 6 & 2.4 \\
\hline & Daily laborer & 4 & 1.6 \\
\hline
\end{tabular}

\subsection{Obstetrics Related Characteristics}

Two hundred forty one $(97.1 \%)$ of mothers had a regular antenatal visit and the remaining $2.8 \%$ had less than 4 visit. About 69(27.8\%) primpara, 149 (60.1\%) Multipara and 30(12.1\%) mothers have Grand multiparty. Most of the respondent's GA at delivery was (37-42 wks) and it was 203(81.9\%). Most of the mothers $97.6 \%$ were RH positive. From the respondents, 32(12.9\%) of mothers had prolonged labor and 21 (8.5\%) were diagnosed to have pre-eclampsia. The labor was started spontaneously in $223(89.9 \%)$ of mothers and the rest $107(43.1 \%)$, 94(37.9\%) and 47(19.0\%) were delivered cesarean section, Spontanous vaginal delivery (SVD) and instrumental delivery respectively. The fetal distress happened at first and second stage labor was $45(18.1 \%)$.

Regarding medical conditions of respondent mothers $23(9.3 \%), 13(5.2 \%)$ and $5(2.0 \%)$ had anemia, gestational diabetes mellitus (GDM) and Hepatitis B virus respectively. (Table 2) 
Table: 2 Obstetric characteristics of women who delivered at the study time in SPHMMC delivery ward

\begin{tabular}{|c|c|c|c|}
\hline \multicolumn{2}{|l|}{ Variable } & Frequency & Percent \\
\hline \multirow[t]{2}{*}{ ANC follow up } & Yes & 246 & 99.2 \\
\hline & No & 2 & .8 \\
\hline \multirow[t]{2}{*}{ No of ANC follow up } & $<4$ visit & 7 & 2.8 \\
\hline & $>4$ visit & 241 & 97.1 \\
\hline \multirow{3}{*}{ Parity* } & Primi parity & 69 & 27.8 \\
\hline & Multi Parity & 149 & 60.1 \\
\hline & Grand multiparty & 30 & 12.1 \\
\hline \multirow[b]{2}{*}{ Gestational age } & 37-42wks & 203 & 81.9 \\
\hline & $>42 \mathrm{wks}$ & 45 & 18.1 \\
\hline \multirow[t]{2}{*}{ RH factors } & Negative & 6 & 2.4 \\
\hline & Positive & 242 & 97.6 \\
\hline \multirow[t]{2}{*}{ Obstructed Labor } & Yes & 18 & 7.3 \\
\hline & No & 230 & 92.7 \\
\hline \multirow[t]{2}{*}{ Prolonged Labor } & Yes & 32 & 12.9 \\
\hline & No & 216 & 87.1 \\
\hline \multirow{2}{*}{$\begin{array}{l}\text { Intra Uterine Growth } \\
\text { Retardation }\end{array}$} & Yes & 12 & 4.8 \\
\hline & No & 236 & 95.2 \\
\hline \multirow[t]{2}{*}{ Pre-eclapsia } & Yes & 21 & 8.5 \\
\hline & No & 227 & 91.5 \\
\hline \multirow[t]{2}{*}{ Oligohydramius } & Yes & 17 & 6.9 \\
\hline & No & 231 & 93.1 \\
\hline \multirow[t]{2}{*}{ Onset of labor } & Spontaneous & 223 & 89.9 \\
\hline & Induce & 25 & 10.1 \\
\hline \multirow[t]{2}{*}{ Duration of labor** } & $<12$ & 174 & 70.2 \\
\hline & $>12$ & 74 & 29.8 \\
\hline \multirow[t]{2}{*}{ Fetal Distress } & Yes & 45 & 18.1 \\
\hline & No & 203 & 81.9 \\
\hline \multirow[t]{2}{*}{ PreRupture of Membrane } & Yes & 37 & 14.9 \\
\hline & No & 211 & 85.1 \\
\hline \multirow{2}{*}{$\begin{array}{l}\text { Prolonged PreRupture of } \\
\text { membrane }\end{array}$} & Yes & 14 & 5.6 \\
\hline & No & 234 & 94.4 \\
\hline \multirow{2}{*}{$\begin{array}{l}\text { Meconium } \\
\text { amniotic fluid }\end{array}$} & Yes & 30 & 12.1 \\
\hline & No & 218 & 87.9 \\
\hline \multirow[t]{3}{*}{ Grade of MSAF } & G I & 12 & 4.8 \\
\hline & G II & 10 & 4.0 \\
\hline & G III & 8 & 3.2 \\
\hline
\end{tabular}

*Prolonged labour defined by the international classification for disease (ICD10) as |progress of slower than one $\mathrm{cm}$ per or as irregular or poor uterine contractions or as a labor with regular uterine contractions for more than 12 hours and/or as a cervical dilation of ten cm for more than three hours. ${ }^{12}$

** parity status of women exposure define as number of pregnancy greater than 20 weeks of GA whereby multiparty was defined as a parity of 2 to 4 deliveries while grand multiparty was defined as a parity of 5 or more deliveries. ${ }^{13}$

\subsection{Prevalence of meconium stained amniotic fluid}

The prevalence of MSAF was found to be 30(12.1\%) with [95\%CI $=8.1-16.5]$. From those 30 delivered mothers with MSAF, 8(26.7\%), 10(33.3\%) and 12(40.0\%) were diagnosis with grade 3, grade 2 and grade 1 MSAF respectively. (Figure: 1) Among the 30 newborns delivered from MSAF, 29 were resuscitated and the rest one received immediate newborn care. From those of resuscitated infant 27 of them were transferred to NICU and three of them stayed with their mother. Most of newborns transferred to NICU $10(37.0 \%)$ were diagnosed to have Asphyxia and the rest were diagnosed with respiratory distress and neonatal sepsis. 


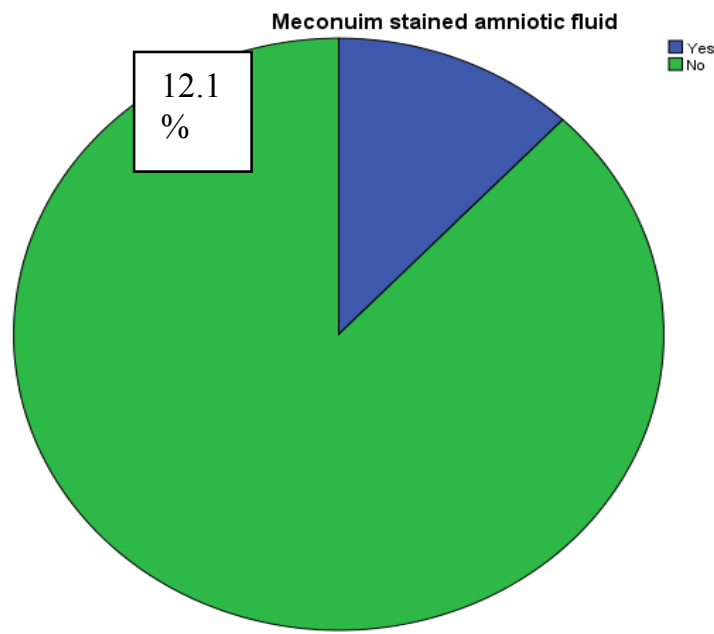

Figure: 1: Prevalence of meconium stained amniotic fluid women who gave birth at study time in SPHMMC delivery ward $(n=248)$

\subsection{Factors Associated with Meconium Stained Amniotic Fluid}

The associations between independent and dependent variables were analyzed. In the binary Logistic regression; obstructed labor, prolonged labor, preeclampsia, Intra Uterine Growth Retardation IUGR, Oligohydramius, Duration of labor, onset of labor, PROM, PPROM, Hepatitis B, were associated at p-value less than 0.2 . On the other hand fetal distress, GA, DM were not significant in this study. (Table 3)

Table: 3. Binary logistic analysis cross tab and COR women who gave birth at study time in SPHMMC delivery ward.

\begin{tabular}{|c|c|c|c|c|c|}
\hline \multirow[t]{2}{*}{ Variable } & & \multicolumn{2}{|c|}{ MSAF } & \multirow[t]{2}{*}{ Significant } & \multirow[t]{2}{*}{$\operatorname{COR}(95 \% \mathrm{CI})$} \\
\hline & & No & Yes & & \\
\hline \multirow[t]{2}{*}{ Obstructed Labor } & Yes & $12(4.8 \%)$ & $6(2.4 \%)$ & .007 & $4.292(1.476-12.478)$ \\
\hline & NO & $206(83.1 \%)$ & $24(9.7 \%)$ & 1 & 1 \\
\hline \multirow[t]{2}{*}{ Prolonged Labor } & Yes & $21(8.5 \%)$ & $11(4.4 \%)$ & .000 & $5.331(2.279-12.478)$ \\
\hline & No & $197(79.4 \%)$ & $19(7.7 \%)$ & 1 & 1 \\
\hline \multirow{2}{*}{$\begin{array}{l}\text { Intra Uterine } \\
\text { Growth } \\
\text { Retardation }\end{array}$} & Yes & $8(3.2 \%)$ & $4(16 \%)$ & .031 & $4.038(1.476-12.478)$ \\
\hline & No & $210(84.7 \%)$ & $26(10.5 \%)$ & 1 & \\
\hline \multirow[t]{2}{*}{ Pre-eclampsia } & Yes & $14(5.6 \%)$ & $7(2.8 \%)$ & .004 & $4.435(1.624-12.109)$ \\
\hline & No & $204(82.35)$ & $23(9.3 \%)$ & 1 & \\
\hline \multirow[t]{2}{*}{ Oligohydramius } & Yes & $10(4.0 \%)$ & $7(2.8 \%)$ & .001 & $6.330(2.199-18.227$ \\
\hline & No & $208(83.9 \%)$ & $23(9.3 \%)$ & 1 & \\
\hline \multirow[t]{2}{*}{ Onset of labor } & Spontaneous & $200(80.6 \%)$ & $23(9.3 \%)$ & & \\
\hline & Induce & $18(7.3 \%)$ & $7(2.8 \%)$ & .014 & $2.299(1.037-5.100)$ \\
\hline \multirow[t]{2}{*}{ Duration of labor } & $<12 \mathrm{hr}$ & $161(64.9 \%)$ & $13(5.2$ & & \\
\hline & $>12 \mathrm{hr}$ & $57(23.0 \%)$ & $17(6.9 \%$ & .001 & $3.694(1.689-8.080)$ \\
\hline \multirow[t]{2}{*}{ PROM } & Yes & $24(9.7 \%)$ & $13(5.2 \%)$ & .000 & $6.181(2.675-14.282)$ \\
\hline & No & $194(78.2 \%$ & $17(6.9 \%)$ & 1 & \\
\hline \multirow[t]{2}{*}{ PPROM } & Yes & $7(2.8 \%)$ & $7(2.8 \%)$ & .000 & $9.174(2.956-28.473)$ \\
\hline & No & $211(85.1 \%)$ & $23(9.3 \%)$ & & \\
\hline \multirow[t]{2}{*}{ Hepatitis B } & Yes & $3(1.2 \%)$ & $2(0.8 \%)$ & .081 & $5.119(820-31.976)$ \\
\hline & No & $215(86.7 \%)$ & $28(11.3 \%)$ & & \\
\hline
\end{tabular}

A accordingly multiple logistic regression analysis were done and revealed that, those mothers who had premature rapture of membrane were 7.6 times higher rates of developing MSAF during labor than mothers without PROM [AOR=7.6, 95\%C1=2.525-23.00].

Delivered mothers with preeclampsia were 5.4 times more prone to have MSAF as compared to those who didn't have $[\mathrm{AOR}=5.4,95 \% \mathrm{Cl}=1.579-19.145]$. Mothers who had PPROM were 5.1 times higher rates of developing MSAF during labor as compared to those who didn't have [AOR=5.1, 95\% $1=1.221-22.122]$.

Mothers in labor for more than $12 \mathrm{hrs}$ had about 3.2 times more potentially to develop MSAF than those who had less than $12 \mathrm{hrs}$ [AOR=5.1, 95\% $\mathrm{C} 1=1.221-22.122]$.

The probability of developing MSAF in prolonged labor was 3 times to have MSAF than without prolonged 
labor $[\mathrm{AOR}=3.0,95 \% \mathrm{CI}=1.075-8.857]$. (Table 4)

Table: 4 Multi logistic regression analysis variables $\mathrm{P}$ value $<0.05$ women who gave birth at study time in SPHMMC delivery ward $(\mathrm{n}=248)$.

\begin{tabular}{|c|c|c|c|c|c|}
\hline \multirow[t]{2}{*}{ Variables } & & \multicolumn{2}{|l|}{ MASF } & \multirow[t]{2}{*}{ Significant } & \multirow[t]{2}{*}{ AOR95\%CI } \\
\hline & & No & Yes & & \\
\hline \multirow[t]{2}{*}{ PROM } & Yes & $24(9.7 \%)$ & $13(5.2 \%)$ & $.000 * * *$ & $7.622(2.525-23.00)$ \\
\hline & No & $194(78.2 \%$ & $17(6.9 \%)$ & 1 & \\
\hline \multirow[t]{2}{*}{ Pre- eclampisa } & Yes & $14(5.6 \%)$ & $7(2.8 \%)$ & $.007 * * *$ & $5.498(1.579-19.145)$ \\
\hline & No & $204(82.35)$ & $23(9.3 \%)$ & 1 & \\
\hline \multirow[t]{2}{*}{ PPROM } & Yes & $7(2.8 \%)$ & $7(2.8 \%)$ & $.026 * * *$ & $5.1(1.221-22.122)$ \\
\hline & No & $211(85.1 \%)$ & $23(9.3 \%)$ & & \\
\hline \multirow{2}{*}{$\begin{array}{l}\text { Duration } \\
\text { labor }\end{array}$} & $<12 \mathrm{hr}$ & $161(64.9 \%)$ & $13(5.2$ & & \\
\hline & $>12 \mathrm{hr}$ & $57(23.0 \%)$ & $17(6.9 \%$ & $.018 * * *$ & $3.268(1.22-8.723)$ \\
\hline \multirow{2}{*}{$\begin{array}{l}\text { Prolonged } \\
\text { Labor }\end{array}$} & Yes & $12(4.8 \%)$ & $6(2.4 \%)$ & $.036 * * *$ & $3.085(1.075-8.857)$ \\
\hline & No & $206(83.1 \%)$ & $24(9.7 \%)$ & 1 & \\
\hline
\end{tabular}

$* * *$ Variables significantly associated with dependent variable by multiple logistic regression analysis on the basis of p-value less than 0.05

\section{DISCUSSIONS}

This study assessed the prevalence of MSAF and its contributing factor with mothers delivered at SPHMMC. The result of this study was found to be $12.1 \%$. The finding of this study was harmonious with the study conducted at Jimma University specialized hospital (15.4\%). ${ }^{9}$ Furthermore the study was congruent with the finding from Ghana and St.philomenas hospital where $(12.42 \%),(8.96 \%)$ respectively ${ }^{8,14}$.

On the contrary, this result was lower than the study conducted at Bahirdar Felegehiwot hospital and the finding was (17.8). ${ }^{11}$ Moreover, the finding was lower in prevalence of MSAF in which study conducted in Nigeria University it was $(20.4 \%){ }^{15}$.The variation might be due to the strategy of the government in reducing NMR.

On the other hand, the prevalence of MSAF in this finding was higher than the study finding in Pakistan $(7.7 \%)^{16}$. Discrepancy between the studies exists because this study was conducted at level of the hospital which covers dense population and where delivering mothers referred after developing complication.

More importantly the study noted that a significant association between variables. Mothers with preeclampsia were almost 5.5 times more likely to develop MSAF. This finding was corresponding with study findings in Felgehiwot comprehensive hospital, $[\mathrm{AOR}=3.45,95 \% \mathrm{CI}=1.26-9.37] .{ }^{11}$ This might be due to the possibility of placental factor in mothers with preeclampsia that results in intrauterine hypoxia.

Prolonged labor showed statistically significant association with MSAF [AOR $=3.0,95 \% \mathrm{CI}=1.075-8.857]$. The finding was congruent with findings at India and Felegehiwot hospital $[\mathrm{AOR}=3.495 \% \mathrm{CI}=1.086-9.354]$ [25], $[\mathrm{AOR}=7.1,95 \% \mathrm{Cl}=1.67-29.68]$ respectively. ${ }^{10,11}$ This reason revealed that when labor duration prolong impose stress to the fetus then the intestine starts to relax and meconium passed.

Furthermore the study shows delivering mothers with PROM were 5.1 times more prone to have MSAF. This study was comparable with the study conducted in Nigeria university teaching hospital. ${ }^{15}$

In this finding among MSAF delivery, 90\% new born were transferred to NICU immediately after birth, $83 \%$ of these were diagnosed to respiratory problem and neonatal sepsis at NICU. This study share the study conducted at Jimma University specialized hospital the majority of newborn with MSAF had complicated with MAS. ${ }^{9}$

\section{Conclusions and recommendation}

This study concluded that MSAF was common problem which impose adverse condition to the fetus and newborn. And revealed that Prolonged labor, Preeclampsia and PROM had a significant association for the incidence of MSAF. Therefore, early detection by adhering to partograph and early decision making for intervention is suggested to reduce the incident of prolonged labor and PROM. In addition to this it would be better to stick to protocols or preeclampsia chart for mothers with preeclampsia and strengthen the action of feedback to their catchment heath centers. Furthermore finding will be used as an input or a baseline for other/further study.

\section{Limitation of the study}

This study shares the limitations of cross-sectional studies and hence may not be possible to establish a temporal relationship between MSAF and explanatory variables. 


$\begin{array}{ll}\text { ABBREVIATION } \\ \text { ANC } & \text { Antenatal Care } \\ \text { APH } & \text { Ante Partum Hemorrhage } \\ \text { C/S } & \text { Caesarean Section } \\ \text { DM } & \text { Diabetes Mellitus } \\ \text { GA } & \text { Gestational Age } \\ \text { HMIS } & \text { Health Management Information System } \\ \text { HTN } & \text { Hypertension } \\ \text { MSAF } & \text { Meconium Stained Amniotic Fluid } \\ \text { MAS } & \text { Meconium Asphyxia Syndrome } \\ \text { MSL } & \text { Meconium Stained Liquor } \\ \text { NICU } & \text { Neonatal Intensive Care Unit } \\ \text { NMR } & \text { Neonatal Mortality Rate } \\ \text { PROM } & \text { Premature Rupture of Membrane } \\ \text { PPROM } & \text { Prolonged premature Rupture of Membrane } \\ \text { PNA } & \text { Prenatal Asphyxia } \\ \text { RDS } & \text { Respiratory Distress Syndrome } \\ \text { SVD } & \text { Spontaneous Vaginal Delivery } \\ \text { SPHMMC } & \text { St. Paul's Hospital Millennium Medical College } \\ \text { SPSS } & \text { Stastical Package for social Sciences }\end{array}$

\section{Ethical consideration}

Ethical clearance was obtained from institutional review board St. Paul Hospital Millennium Medical College PM 24/524. Formal letter obtained for cooperation of medical service administrative office of St Paul's hospital millennium medical college. Then the participants were informed about the purpose of the study, the importance of the study, full confidentiality, withdraws at any time and written consent had obtained prior to data collection. Privacy and confidentiality of information given by each respondent were kept properly and number code was used otherwise names were not recorded.

\section{Authors Contribution}

All authors made significant contributions in every step of the research. Mainly HAH, FN, EN and BA developed proposal, collecting and analyzing the data and drafted the manuscript. RW performed methodology and quality management. RN and $\mathrm{MH}$ contributed in interpretation of data supervising the data collection, reviewed the study design and took drafted the manuscript. All authors were read and revised it critically the final version of the paper and approved for publication.

\section{REFERENCE}

1. Mundhra,R.Agarwal,M.(2013).Fetal Outcome in Meconium Stained Deliveries. Journal of Clinical and Diagnostic Research. 2013 Dec, Vol-7(12): 2874-2876.

2. Qadir S, Jan S, Chachoo JA, Parveen S. Perinatal and neonatal outcome in meconium stained amniotic fluid. Int J ReprodContraceptObstet Gynecol.2017;5(5):1400-5.

3. Shaikh EM, Mehmood S, Shaikh MA. Neonatal outcome in meconium stained amniotic fluid-one year experience.JPMA. 2010;60(9):711-4

4. Desai D, Maitra N, Patel P. Fetal heart rate patterns in patients with thick Meconium staining of amniotic fluid and its association with perinatal Outcome. Int J ReprodContraceptObstet Gynecol. 2017;6(3):1030-5.

5. Dargaville, P.A., \& Copnell, B. (2006). The epidemiology of meconium aspiration syndrome: incidence, risk factors, therapies, and outcome. Pediatrics, 117 5, 1712-21

6. Becker S, Solomayer E, Dogan C, Wallwiener D, Fehm T. Meconium-stained amniotic fluid Perinatal outcome and obstetrical management in a low-risk suburban population. European Journal of Obstetrics \& Gynecologic and Reproductive Biology. https://doi.org/10.1016/j.ejogrb.2006.05.032

7. Soni A, Vaishnav GD, Gohil J. Meconium stained amniotic fluid, its ignificance and Obstetric Outcome. Med Sci. 2015;4(1):1861-68.

8. Mahapatro AK, Ghose S. Obstetrics outcome at term in meconium stained amniotic fluid-retrospective study. Int J pharm Bio Sci. 2014:866-71.

9. Woldie, Mirkuzie. (2016). Meconium Stained Amniotic Fluid: Factors affecting Maternal and Perinatal Outcomes at Jimma University Specialized Teaching Hospital, South West Ethiopia. Gynecologic and Obstetrics. 6. 1-6. 10.4172/2161-0932.1000394.

10. ER - Hutton EK, Thorpe J. Consequences of meconium stained amniotic fluid: what does the evidence tell us?Early Human Development https://doi.org/10.1016/j.earlhumdev.2014.04.005 
11. Addis D, Asres A, Gedefaw G, Asmer S. Prevalence of meconium stained amniotic fluid and its associated factors among women who gave birth at term in Felege Hiwot comprehensive specialized referral hospital, North West Ethiopia: a facility based cross-sectional study. BMC Pregnancy and Childbirth 2018;18(429).

12. Muniro, Z., Tarimo, C.S., Mahande, M.J. et al. Grand multiparity as a predictor of adverse pregnancy outcome among women who delivered at a tertiary hospital in Northern Tanzania. BMC Pregnancy Childbirth 19, 222 (2019). https://doi.org/10.1186/ s12884-019-2377-5

13. World Health Organization: International Statistical Classification of Diseases and Related Health Problems: ICD-10, 10. rev. 2008th edition. Geneva: World Health Organization; 2009.

14. Singh P, Soren SN. Perinatal outcome in meconium stained amniotic fluid. Med Pulse - International Medical Journal. 2017; 4 (1)(0613).

15. David A, Njokanma O, Iroha E. Incidence of and factors associated with meconium staining of the amniotic fluid in a Nigerian University teaching hospital. J ObstetGynaecol. 2006; 26 (6):518-20.

16. Ali L, Anbreen T, Yasir R. Pregnancies with meconium stained liquor. Journal of Surgery Pakistan (International). 2014; 19 (1)(3134). 